\title{
ALGUNS ASPECTOS DO FURTO NEURÓTICO
}

(Contribuição ao estudo do crime e do criminoso, à luz da psicánalise)

\author{
Napoleão L. Teixeira \\ Professor de Medicina Legal da Faculdade de \\ Direito da Universidade do Paraná.
}

\section{1 - NA LITERATURA}

Quem leu EÇA deve, sem dúvida, recordar-se de interessante conto "Singularidades de uma rapariga loira" - no qual fala de criatura estranha e bela, de original temperamento, "muito simples, quase indiferente, cheia de transigências". Dona de "natureza débil, agüada, nula" tinha, por outro lado, "o caráter loiro como os cabelos - si é certo que o loiro é uma côr fraca e desbotada": falava pouco, "sorria sempre com seus brancos dentinhos, dizia a tudo - pois sim!" 
Que, saíndo as compras, se valia da distração dos caixeiros para surripiar caixa com lenços ou anel de brilhantes. E até mesmo, em partida de cartas familiar, junto ao noivo embevecido, guardava, candidamente, peça d'oiro que, acaso, ao virginal colo the viesse tombar.

Ladra - dirão alguns; cleptômana - pensarão outros.

Pontos de vista.

\section{2 - ENTRANDO NO ASSUNTO}

Haverá mesmo isso de alguém furtar por doença, furtar em razão de impulso patológico?

A resposta é afirmativa. Trata-se quase sempre - quase sempre, não sempre - de criminoso neurótico. Seu ato (que tem o mesmo mecanismo psicológico do crime) encontra orígem em raízes inconcientes.

Face a determinado objeto, vê-se compelido a apanhá-lo, e escondê-lo, levá-lo consigo. Fôrça imperiosa, tirânica, soberana, determina-lhe a ação. Resiste, por vezes. Sabendo, entretanto, de antemão, perdida a batalha. Tamanha a ansiedade por essa luta acarretada, que prefere ceder logo, obedecer ao impulso, praticar o ato, do que lhe advém, de imediato, grande e desafogador alívio.

Tem, não raro, tendência a furtar objetos diferentes. Pode fazê-lo, contudo, em relação a determinado objeto, sempre o mesmo, a que empresta significado simbólico. Excepcionalmente pura, a cleptomania (designação criada por MARC), é' vez por outra, encontradiça em colecionador (mono-clepto-colecionador, de MINGAZZINI), ou em fetchistas sexuais.

\section{3 - CASOS CONCRETOS}

De uma senhora, em Paris, refere-se haver sido surpreendida, em grande "magasin", a furtar. Furtava esponjas, só esponjas. Tinha, em casa - descobriu-se, depois - um armário cheio delas, novas, de todas as côres e formas, ainda com o envólucro de fábrica. 
Certo cidadão, nos Estados Unidos, fazia o mesmo em relação a mêias femininas: guardava-as, às centenas, religiosamente arrumadas, em recanto tranqüilo, onde se comprazia, horas a fio, em doce e suave contemplação.

Conta o Prof. HENRIQUE ROXO, nosso Mestre, haver conhecido, na capital francêsa, dama brasileira de alta sociedade, que só saía acompanhada de empregado, que ia repôr, no dia seguinte, as coisas que ela era impulsionada a furtar.

Não faz muito, noticiou certa imprensa carioca, com o escândalo costumeiro, haver sido apanhada pessoa rica, de trato, bem nascida, da "haute-gomme" sulina, ao levar, oculta sob o "tailleur", custosa blusa, tiradas, às escondidas, da loja em que entrara.

Curiosa a frequência da cleptomania entre criaturas do sexo feminino. Cumpre assinalar que o impulso mórbido ao furto mais se acirra nos dias que precedem o fluxo menstrual, ou durante as épocas em que o instinto sexual se exacerba - razão da periodicidade do mesmo.

Como se vê, o cleptômano não elege, obrigatòriamente, artigos valiosos. Não raro, prefere-os até de baixo custo, pequenos. Se bem possa ocorrer - como em rumoroso e notório caso local, no qual o observado, indivíduo em boa situação, dono de razoáveis haveres, bem situado na vida - se apropriou, indèbitamente, de grande, pesada e vistosa banheira...

\section{4 - COMO AS COISAS PASSAM}

O cleptômano pode ignorar o que fêz. Por que o fêz. Constatar, atônito, que o fêz - eis tudo.

Vindo alguém, mais tarde - autoridade por exemplo interrogá-lo, e não querendo passar por "anormal", engendra explicação (tècnicamente, diriamos - "racionaliza"), para encher os vazios de sua história. Exemplo dado por psicanalistas ianques: moça, acusada de furtar livros e gravuras, foi prêsa ao roubar edição barata do "Fausto". Ao Juiz, declarou que o fizera "porque pretendia ser atriz e o livro lhe poderia vir a 
ser útil..." Análise revelou que, para ela, furtar significava adquirir, pela violência, coisas que a vida lhe negara. No ato de furtar, seus desejos recebiam, de modo simbólico, satisfação substitutiva.

\section{5 - FURTO INFANTIL}

Ilustrativo o caso, descrito por Mira: adolescente de 13 anos tirava, frequentemente, os lapis guardados na gaveta pelo professor da classe, ao qual, aparentemente, estava ligado por bom afeto. Tratava-se de rapaz de recursos, que não precisava dêsses lapis. Tirava-os e entretinha-se a mordê-los e a jogá-los, aos pedacinhos, à rua. Rápida investigação psicanalítica pôs de manifesto o seguinte: êste menino, filho de rico homem de negócios, fôra, por êste, duramente reprimido em várias ocasiões, "por sua curteza de espírito e falta de valor". 0 adolescente admirava e, ao mesmo tempo, temia e odiava o pai ("ambivalência") ; considerava que nada podia fazer para libertar-se de sua opressão. Nessas condições, o fato de o professor ter, por acaso, o rosto parecido com o do pai - além da autoridade comum - fêz com que, no seu subconsciente, surgisse a tendência, impulsiva, a praticar o delito simbólico: "roubar e destroçar os lápis do professor", conclui Mira, "simboliza destruir o órgão viril do pai, livrando-se, assim, da coação que aquêle exercia".

Frise-se serem simbólicos os furtos infantís, em grande número - lugar à parte para o "furto lúdico" e o "furto por imitação", encontradiços em escolares. Expressam, aquêles, desejos e sentimentos de "possuír alguma coisa que está faltando" à criança, como seja: amor negado por pais demasiado frios ou desconhecidos ("fome de amor") ; ânsia de afirmação da personalidade, conquista de sentimento de valor do "eu", da masculinidade "protesto viril", de ADLER ) ou da feminilidade tudo isso traduzindo-se sob forma de apropriação de objetos aparentemente indiferentes. Razão de, com acêrto, frisarem muitos autores ser o furto, no menor, em casos assim, puramente REATIVO: seja para compensar-se de afeto que não teve, que não tem mais ou que não logrou alcançar -- havendo então 
lugar para falar-se em "furtos de consolação, de vingança, de ciúme ou de reação a complexo de inferioridade". Acreditando acharem, dest'arte, explicação para a circunstância de a maioria de furtos ocorrerem entre crianças pobres, abandonadas, escorraçadas, filhas de lares infelizes - como "compensação" a desajustamentos afetivos e sociais.

6 - ACREDITAM OS PSICANALISTAS, na sua desculpável ânsia de tudo pretenderem explicar, que, na impulsão a roubar, a incendiar (piromania ou incendiarismo), a quebrar (frangofilia), etc. - 0 ato se realizaria em função de um sentimento culposo e do sofrimento dêste decorrente. Indivíduos que não lograram liquidar completamente seu complexo-de-Édipo, detêm-se, uns, na fase de atração sexual pela mãe; outros, na fase de ódio ao pai. Em consequência do que, o super-ego exprobra o ego, gerando, nêste, um sentimento, inconsciente, de culpa ( $S H U L D G E F U ̈ H L$ ), acompanhado de angústia e necessidade de punição (STRAFBEDÜRFNIS, de Reik).

A êsse sentimento de culpa reagiria o indivíduo pela execução do ato anti-social que seria, assim, um meio de tornar consciente a culpa e propiciar punição desejada. Humilhação sofrida, escândalo, a polícia, a cadeia mesmo - viriam, até certo ponto, trazer alívio à angústia gerada por êsse ínsito sentimento gerado por culpas infantis impunes. $O$ ato anti-social traduziria, portanto, inconsciente desejo de renovar, efetiva ou simbòlicamente, faltas não castigadas na infância, de maneira a ensejar repressão - crime e castigo, ao mesmo tempo. Por outras palavras, paradoxal que pareça, cometeria o crime movido pelo "desejo" (digamos assim) de que o pilhassem, envergonhassem, castigassem, prendessem...

Na classificação de ALEXANDER e STAUBB, de "atos aberrantes que têm o mesmo mecanismo psicológico do crime", vem, a cleptomania enquadrada nas "ações criminais neuròticamente condicionadas", entre os "delitos por autocoação" (o impulso coativo surgiria no campo do Eu como um corpo estra- 
nho, sem sentido, isolado do restante da consciência). Transparece como legítimo ato compulsivo. $\left({ }^{*}\right)$

$\mathrm{Na}$ classificação de GENIL-PERRIN, inclui-se o cleptômano, entre os "criminosos neuróticos". Na classificação do saudoso PORTO-CARRERO, mais interessante a nosso vêr, vem a cleptomania e demais furtos neuróticos, enquadrados entre os crimes por ação auto-punitiva do super-ego.

Nêstes, como nos demais casos em que o sentimento culposo é que leva o indivíduo ao crime, vamos encontrar aquêles criminosos que não sentem remorsos, que se mostram calmos e dormem tranquilos depois do crime. Presos, confessam prontamente o que fizeram, tal é a ânsia de que os punam. Ao passo que Reik assinala uma "angústia prévia" (VORANGST) e uma "angústia final" (ENDANGST), antes e depois de haverem confessado, descreve Freud um "prazer prévio" (VORLUST) e um "prazer final" (ENDLUST), anteriormente e posteriormente à confissão.

7 - PARA FINALIZAR

Há os que disso descrêm, e são muitos.

CLEMENTINO FRAGA, por exemplo, recorda ser o médico, não raro, obrigado a suportar "ilustres esquizóides" que, cordialidade, o detestam, rezando, como rezam, por azêdo breviário que aconselha "defender a pele contra o médico que crê na Medicina e o coração contra a mulher que acredita no amor..." Ensina, a seguir, que para estar em boas contas com

(*) ... de que são tipo os sintomas da psiconeurose compulsiva, obsessiva, coacta ou anancástica. Poderiam existir fora da neurose? E' pelo menos o que alguns pretendem admitir: casos previstos por alguns códigos (o francês, por exemplo), "em que uma fôrça irresistível comandou o ato".

Em nosso livro sôbre o suicidio, dedicamos trechos ao estudo de indivíduos que são levados à autoquíria pela fôrça irresistível da compulsão ("O Suicídio, em face da psicopatologia, da literatura, da filosofia e do Direito - Estudo Psiquiátrico, médico-legal e profilaxia" - volume de 176 páginas, $2 .^{\circ}$ milheiro) 
a Sociedade, precisa o médico, ademais de outras atitudes, aceitar o eufenismo de certas doenças, como a CLEPTOMANIA, "só diagnosticada na alta sociedade, porque ,entre os chamados "granfinos" não há viciosos, amigos do alheio; só há... doentes". Termina perguntando: "quem já viu cleptomaníaco em meio pobre, entre os humildes?... "Pergunta a que, logo a seguir, êle mesmo responde: "Sempre na barra, a desigualdade social: o furto do rico leva à casa-de-saúde; o do pobre, é... simples caso de polícia!"

Curiosas palavras, sem dúvida. $\mathrm{E}$ dignas de respeito,vindas de quem vêm. Mas, não totalmente de acôrdo com a realidade, tão conhecida de nós outros que, como psiquiatras, militamos na clínica. 